\title{
Psychological Inflexibility and Child Anxiety
}

\author{
Ellin Simon ${ }^{1} \cdot$ Peter Verboon $^{1}$
}

Published online: 31 August 2016

(C) Springer Science+Business Media New York 2016

\begin{abstract}
Psychological flexibility is the main outcome of acceptance commitment therapy. Insight into the usefulness of measuring psychological flexibility is an important step to enable studies on the effectiveness of acceptance commitment therapy in middle-aged children ( $8-10$ years). For this purpose, we examined the factor structure, the construct validity and the reliability of the Avoidance and Fusion Questionnaire for Youth. The Avoidance and Fusion Questionnaire for Youth taps psychological inflexibility (the opposite of psychological flexibility) in children and adolescents. Although the questionnaire has been extensively validated in older children, this is not the case for middleaged children. The Avoidance and Fusion Questionnaire for Youth contains 17 items and is constituted of the subscales cognitive fusion, experiential avoidance and behavioral ineffectiveness. A shortened 8-item version also exists, the Avoidance and Fusion Questionnaire for Youth-8, which does not distinguish between these subscales. We performed a confirmatory factor analysis. Additionally, we assessed the relationship between psychological flexibility and child anxiety. Children, aged 8-10 years, were recruited via regular primary schools. Of the 459 approached children, $267(58 \%)$ parents signed informed consents for their children (Age: $M=9.18 ; S D=.79$; Sex: $n_{\text {boys }}=137,51 \%$ ). Children completed the questionnaires during regular classes. In this sample, the 17-item version of the Avoidance and Fusion Questionnaire for Youth was less appropriate for measuring psychological inflexibility than the 8-item
\end{abstract}

Ellin Simon

ellin.simon@ou.nl

1 Faculty of Clinical Psychology and Educational Sciences, Open University, Valkenburgerweg 177, Heerlen 6419 AT, The Netherlands version. Furthermore, we found a significant positive relationship between psychological inflexibility and child anxiety. We argue that acceptance commitment therapy would be an interesting candidate for intervening early on in dysfunctional child anxiety, as acceptance commitment therapy's cognitive elements require cognitive skills that children are likely to master early on.

Keywords Child anxiety · Psychological flexibility · Acceptance and commitment therapy · Cognitive level · Avoidance and Fusion Questionnaire for Youth (AFQ-Y)

\section{Introduction}

Acceptance commitment therapy (ACT) is a contextual behavior therapy (Hayes et al. 1999). ACT entails acceptance and mindfulness strategies combined with a commitment to one's valued goals. ACT's main purpose is to improve a person's quality of life, rather than to reduce the person's symptomatology as is the case in traditional Cognitive behavioral therapy (CBT). ACT focuses more strongly on the context of a person's thinking and behavior than traditional CBT (de Groot et al. 2008). The hallmark feature of ACT and thus its most important outcome is psychological flexibility (Hayes et al. 2006). Psychological flexibility (the opposite of psychological inflexibility) entails pursuing important values and goals by choosing behavior in line with these values, while accepting (unpleasant) experiences (Hayes and Strosahl 2004). This is distinct from traditional CBT, which focuses on the removal of symptoms of psychopathology. In recent years, ACT has gained much attention and has proven effective for various 
types of adult psychopathology (Hayes et al. 2006), such as anxiety disorders (Swain et al. 2013). Studies on ACT's effectiveness in children are scarce and smaller-scaled (e.g., Heffner et al. 2002) but generally show promising results (Coyne et al. 2011).

Nevertheless, there are several aspects of ACT that make ACT a valuable intervention type to provide to children. First, it can be theorised that children can be forwarded as active change agents earlier on with ACT than with traditional CBT. That is, the cognitive element of ACT is easier for middle-aged children to grasp than the cognitive element of traditional CBT. Compared to traditional CBT where the focus is on changing the content of cognitions, ACT stimulates clients to have an accepting attitude towards their thoughts (Rector 2013). For this purpose, metaphors are used extensively instead of literal instructions (Murrell et al. 2004). Children are capable of interpreting metaphors from 7 years of age onward (Billow 1981; McCurry and Hayes 1992), and the use of metaphors in children is empirically supported (Heffner et al. 2003). Changing the content of cognitions, as is done in traditional CBT, however, requires hypothetico-deductive reasoning skills (Kendall, Reber et al. 1990; Ronen 1997). This constitutes a form of abstract reasoning consistent with Piaget's stage of formal operational reasoning, which children develop from 11 years of age onwards. The cognitive aspect of traditional CBT may be too difficult for middle-aged children to understand, but rather seems to suit the cognitive level of adolescents and adults. Second, prevention of psychopathology is most commonly aimed at children and ACT's focus on improving psychological flexibility and quality of life suits preventive purposes. Indeed, Fledderus et al. (2010) concluded that a preventive ACT intervention was successful at improving positive mental health by increasing psychological flexibility. Third, intervention and treatment types that include acceptance and mindfulness elements are generally considered highly suitable for children, and Goodman (2005) and Kabat-Zinn (1990) viewed children as more receptive for acceptance and mindfulness strategies than adults.

Because ACT seems a valuable intervention type for children, it is of importance to measure the efficacy of ACT in children. However, studies on psychological flexibility, ACT's main outcome measure, in children are scarce, especially in middle-aged children (Greco et al. 2008). Greco et al. (2005), therefore, developed and validated a self-report questionnaire, the Avoidance and Fusion Questionnaire for Youth (AFQ-Y), to measure psychological inflexibility in children and adolescents. It taps cognitive fusion and experiential avoidance, as well as behavioral ineffectiveness. Cognitive fusion and experiential avoidance are two interrelated processes that produce psychological inflexibility. Cognitive fusion (Luoma and Hayes 2003) has been defined as "the entanglement with the content of private events" (Greco et al. 2008) and experiential avoidance (Hayes and Gifford 1997) as "the unwillingness to experience certain private events and attempts to avoid, manage, alter, or otherwise control their frequency, form or situational sensitivity" (Greco et al. 2008). Behavioral ineffectiveness can be viewed as a consequence or product of cognitive fusion and experiential avoidance. The AFQ-Y has been extensively validated in children aged 10 years and older (Greco et al. 2008). Children are generally capable to complete self-report questionnaires from the age of 7 years onward (Beesdo et al. 2009; Langley et al. 2002; Myers and Winters 2002). To date, information on the usefulness of applying the questionnaire in these younger children is lacking. However, before large scaled efficacy and effectiveness study's on ACT with anxious children can be performed, insight into the role of psychological (in)flexibility in anxious children under the age of 11 is required.

In addition to acquiring insight into the role of psychological (in)flexibility in anxious children under the age of 11 , it is of specific interest to relate psychological flexibility to child anxiety in a sample of middle-aged children. First, anxiety disorders are the most prevalent type of psychiatric disorders in children (Cartwright-Hatton et al. 2006). Second, compared to other types of psychopathology, anxiety disorders have an early age of onset, with a median age of onset of 11 years (Kessler et al. 2005). Third, forwarding children as active change agents in their therapy is of specific importance for child anxiety, as research shows that intervening via the child (instead of via parents) seems to lead to the most favorable outcomes when treating child anxiety (Simon et al. in preparation; Thulin et al. 2014). Finally, child anxiety is an important candidate for preventive interventions, not only because of its high prevalence and its early age of onset, but also because of its negative effects on the quality of life (Achenbach et al. 1995), its high homo- and heterotypic continuity (Simon et al. 2014), and its high societal costs (Bodden et al. 2008). Intervening early is preferably done before the median age of onset of anxiety disorders (i.e.,11 years).

The primary goal of the current study, therefore, was to measure psychological (in)flexibility, and to examine the usefulness of the AFQ-Y in children aged 8-10 years. The second goal was to relate psychological flexibility to child anxiety. For this purpose, we performed a confirmatory factor analysis on the AFQ-Y items within a sample of children between 8 and 11 years old. If the questionnaire proves to be appropriate to measure psychological inflexibility in children between 8 and 11 years of age, this would create the possibility to measure the efficacy of ACT-based treatments in children of this age. In addition, psychological inflexibility was related to symptoms of anxiety in the children, thereby also providing insight into the construct 
validity of the AFQ-Y. We expected to replicate the forwarded factor structure of the AFQ-Y (Greco et al. 2008), thus to identify the three subscales cognitive fusion, experiential avoidance and behavioral ineffectiveness, that, together, constitute psychological inflexibility. We further expected a positive relationship between psychological inflexibility and anxiety symptoms.

\section{Method}

\section{Participants}

Children, aged 8-10 years, were recruited via regular primary schools in the Netherlands. Of the 459 approached children, $267(58 \%)$ parents signed informed consents for their children (Age: $M=9.18 ; S D=.79$; Sex: $n_{\text {boys }}=137$, $51 \%)$ to participate in the study.

\section{Procedure}

This cross-sectional study was approved by the local ethical committee. Headmasters of primary schools were approached by telephone about the study and they received information about the study via e-mail and during a face-toface meeting. The schools provided general information to the parents by e-mail to announce the study. In addition, the teachers sent more detailed information, as well as active consent forms to the parents about the study, also via e-mail.

The children completed the questionnaires during regular classes. A master's student in psychology was present in the classroom to provide help to children if necessary. Completing the questionnaires took the children approximately $25 \mathrm{~min}$.

\section{Measures}

\section{Psychological Inflexibility}

The AFQ-Y is a self-report questionnaire suitable for measuring psychological inflexibility in children and adolescents (Greco et al. 2005). Greco et al. (2008) developed this questionnaire by adapting the Acceptance and Action Questionnaire, which is a self-report questionnaire for psychological inflexibility in adults. The AFQ-Y consists of 17 items that can be rated on a 5-point rating scale ranging from 0 (not at all true) to 4 (very true). The AFQ-Y entails the three subscales Cognitive fusion (e.g., "The bad things I think about myself must be true"), Experiential avoidance (e.g., "I wish I could wave a magic wand to make all my sadness go away"), and Inaction or behavioral ineffectiveness in the presence of unwanted internal experiences (shortened as "Inaction of behavioral ineffectiveness", e.g., "I can't be a good friend when I feel upset"). A total score of psychological inflexibility is obtained by summing all items, with higher scores reflecting a higher amount of psychological inflexibility. Greco et al. (2008) showed a good construct validity of the AFQ-Y, as well as a high reliability $(\alpha=.90)$.

The Avoidance and Fusion Questionnaire for Youth short form, the AFQ-Y8 has been proposed as a short version of the AFQ-Y. It consists of eight items and provides a single total score of psychological inflexibility (i.e., a one-factor model). Greco et al. developed the shortened version of the AFQ for screening purposes (Greco et al. 2005). The items with the highest factor loadings (above .50) were selected and together formed the AFQ-Y8. Although the complete version was used in the current study, we not only analyzed the complete version, but also performed analyses on the eight items of the AFQ-Y that constitute the total score of psychological inflexibility of the AFQ-Y8. The current study used a Dutch version of the AFQ-Y. The Dutch version of the AFQ-Y was constructed by translation and back-translation performed by qualified translators.

\section{Anxiety}

The screen for child anxiety related emotional disorders (Birmaher et al. 1997), Dutch revision by Muris, Merkelbach, Schmidt and Mayer (Muris et al. 1999a), is a questionnaire suitable for screening childhood anxiety disorders, also in community populations. It assesses a range of DSMIV-based anxiety symptoms: panic disorder (13 items), generalized anxiety disorder (9 items), social phobia ( 9 items), separation anxiety disorder (12 items), obsessive compulsive disorder (9 items), post-traumatic stress disorder (4 items), and specific phobia (15 items). The SCARED-R possesses good internal consistency for total and subscales scores (Muris et al. 2004; Muris et al. 2001; Muris et al. 1999b), satisfactory test-retest reliability (Muris et al. 1999) and discriminates well between anxiety problems and other behavioral problems (Muris et al. 2004). This study used the SCARED-71, which adds an extra five items to the social phobia scale (Bodden et al. 2009). The SCARED-71 was found to be a useful anxiety screening tool in primary school children, because the instrument discriminates between children with and without an anxiety disorders and predicts specifically separation anxiety disorder, social phobia and specific phobia (Simon and Bögels 2009). All items were rated on a 3 -point scale $(0=$ almost never, $1=$ sometimes, $2=$ often), and a total score (ranging $0-142$ ) was obtained by adding the items. The homogeneity of the SCARED-71 in this study was good, with $\alpha=.96$ for 
the total score and $\alpha$ ranging from .80 to .87 for the subscales.

\section{Data Analyses}

There were only five missing values $(<0.3 \%)$, which were replaced by the item's median. The internal consistencies of the scales of the AFQ-Y and the SCARED-71 were determined with Chronbach's $\alpha$. The relationship between (the various types of) anxiety and psychological inflexibility (and its subscales) were examined with Pearson's $r$ correlations. Furthermore, independent-samples $t$-tests were applied to explore differences on the variables of psychological inflexibility between children with anxiety scores within the clinical range and children with scores within the "normal" range (Bodden et al. 2009). These analyses were performed with the IBM Statistical Package of Social Sciences (IBM SPSS), version 21.

Confirmatory factor analysis was used to study the factor structure of the AFQ-Y, using the LAVAAN (Rosseel 2012) package for $R$ (R Core Team 2013). We examined the supposed three-factor structure as well as a one-factor structure of the 17-item version of AFQ-Y. Additionally, we examined the one-factor structure of the eight items that constitute the AFQ-Y8, the shortened (8 items) version of the AFQ-Y. We also tested measurement invariance of the AFQ-Y8 one-factor model across boys and girls. To test measurement invariance we ran a number of models based on the procedure proposed by van de Schoot, Lugtig, and Hox (Van de Schoot et al. 2012).

The relative chi-square $\left(\chi^{2} / d f\right)$, the comparative fit index (CFI), the Tucker Lewis Index (TLI) and the root-meansquare error of approximation (RMSEA) were used as fit indices. To determine the presence of a good fit we applied the most stringent cut-off values of $<2$ for the relative chisquare (Arbuckle 2011), >.95 for the CFI and TLI (Kline 1998, 2011; Tabachnick and Fidell 2007) and <.06 for the RMSEA (Arbuckle 2011). Adequate fit is indicated when CFI and TLI exceed .90 and RMSEA is lower than .08.

\section{Results}

\section{Descriptives and Internal Consistencies of Psychological Inflexibility and Anxiety}

The descriptives of the AFQ-17 and the SCARED-71 are depicted in Table 1. Girls $(M=5.84, S D=5.50)$ appeared to have higher scores than boys $(M=4.61, S D=4.96)$ on the SCARED-71 subscale specific phobia, $t(265)=-1.91$, $p=.06$, although this difference was not significant. There were no other sex related differences on any of the AFQ-17 scales and on the SCARED-71 subscales, all $p$ 's >.10.
Table 1 Psychological Inflexibility and Anxiety in School-going Children Aged 8-10 $(N=267)$

\begin{tabular}{lc}
\hline${\text { AFQ- } 17^{\mathrm{a}} \text { and SCARED-71 }}^{\mathrm{b}}(\mathrm{sub})$ scale & $M(S D)$ \\
\hline Cognitive fusion & $6.64(5.23)$ \\
Experiential avoidance & $5.80(4.28)$ \\
Inaction or behavioral ineffectiveness & $6.03(4.87)$ \\
Psychological inflexibility AFQ-17 & $18.46(12.81)$ \\
Psychological inflexibility AFQ- ${ }^{\mathrm{c}}$ & $7.28(5.98)$ \\
Panic disorder & $2.72(3.66)$ \\
Generalized anxiety disorder & $2.60(3.01)$ \\
Social anxiety disorder & $3.37(3.41)$ \\
Separation anxiety disorder & $3.91(3.66)$ \\
Obsessive-compulsive disorder & $3.16(3.37)$ \\
Post-traumatic stress disorder & $1.78(2.14)$ \\
Specific phobia & $5.21(5.25)$ \\
Anxiety (total score SCARED-71) & $22.76(21.31)$
\end{tabular}

a AFQ-17: Avoidance fusion questionnaire (17 items)

b SCARED-71: Screen for child anxiety related emotional disorders (71 items)

c AFQ-8 is the short version of the AFQ-17 and calculates psychological inflexibility on the total of its eight items

The internal consistencies of the AFQ-17 subscales cognitive fusion, experiential avoidance, and inaction or behavioral ineffectiveness were adequate, with $\alpha=.76, \alpha$ $=.72$, and $\alpha=.75$, respectively. The internal consistencies of the total score psychological inflexibility measured with the AFQ-17 total scale and the eight items of the short version AFQ-8 were also adequate to good, with $\alpha=.89$ and $\alpha=.79$, respectively. Cronbach's $\alpha$ did not increase if an item of any of the AFQ-17 was deleted. (Table 2)

\section{Confirmatory Factor Analysis of the Avoidance and Fusion Questionnaire for Youth}

To test the structure of the AFQ-Y we ran several CFA. A summary of the results of the factor analysis with the threefactor and one-factor model is depicted in Table 3. First the three-factor model for the AFQ-Y, derived from three subscales Cognitive fusion, Experiential avoidance, and Inaction of behavioral ineffectiveness (using all 17 items), did not fit the correlation structure well according to all fit criteria $\left(\chi^{2}=245, d f=116 ; \chi^{2} / d f=2.1 ; \mathrm{CFI}=.908\right.$, TLI $=.892$, RMSEA $=.065)$. The more parsimonious one-factor model yielded fit values closely resembling those of the three-factor model $\left(\chi^{2}=229, d f=101 ; \chi^{2} / d f=2.2\right.$; CFI $=.900, \mathrm{TLI}=.886, \mathrm{RMSEA}=.066)$. Testing the difference between these models using the chi-square difference test $\left(\Delta \chi^{2}=16, d f=15 ; p=.382\right)$ shows that the three-factor model cannot be seen as an improvement over the 
Table 2 Correlation between psychological inflexibility and anxiety in school-going children aged 8-10 $(N=267)$

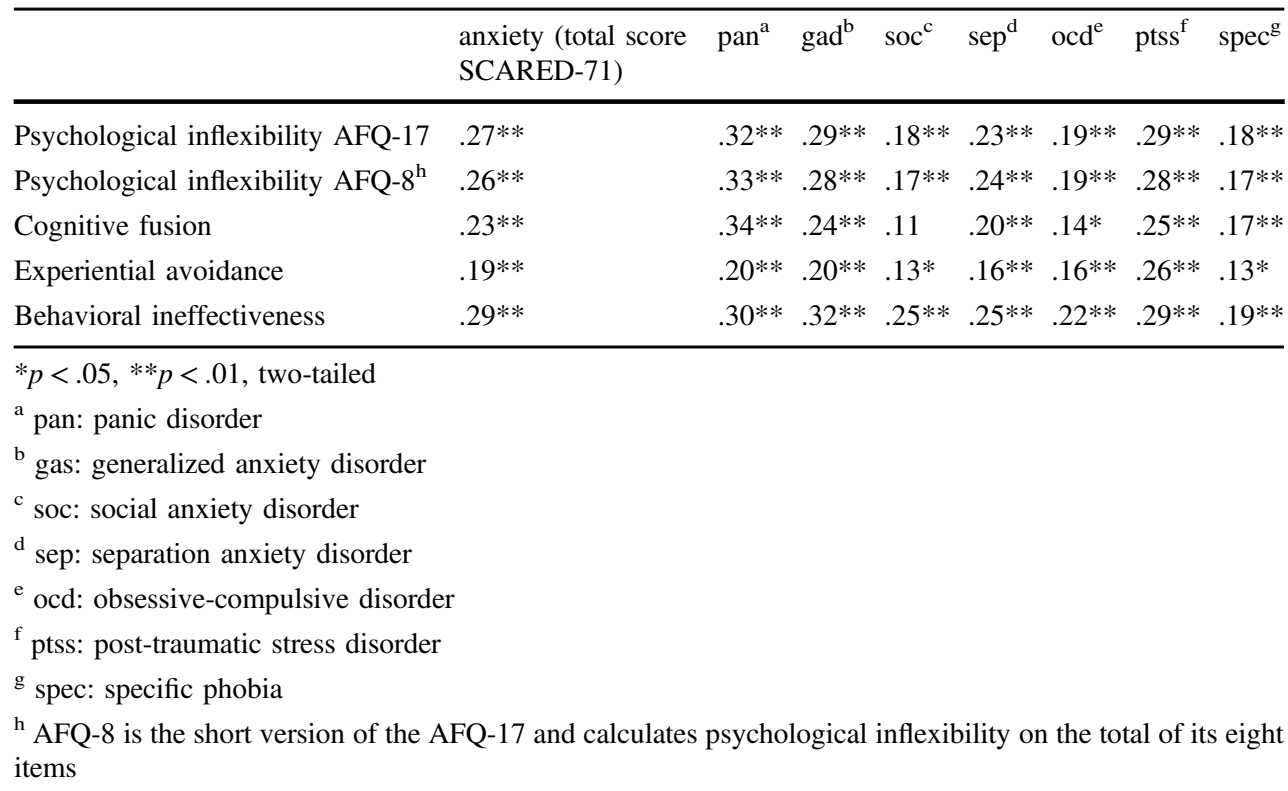

one-factor model. However, the one-factor structure of the shortened AFQ-Y, the AFQ-Y8, fits the data well according to all fit criteria $\left(\chi^{2}=35, d f=20 ; \chi^{2} / d f=1.8 ; \mathrm{CFI}=.969\right.$, $\mathrm{TLI}=.957, \mathrm{RMSEA}=.054)$.

Next, we investigated whether the factorial structure of the shortened AFQ-Y is similar for boys and girls by testing three hierarchical models. The first model tests for configural invariance, which means that the structure of the model is equal across boys and girls while all parameters are free to vary. The second model tests for metric invariance in which the factor loadings are equal across boys and girls. In the third model both loadings and intercepts are constrained to be equal (scalar invariance).

We found evidence for configural invariance $\left(\chi^{2}=69, d f\right.$ $\left.=40 ; \quad \chi^{2} / d f=1.7 ; \quad \mathrm{CFI}=.943 ; \quad \mathrm{RMSEA}=.074\right), \quad$ metric invariance $\left(\chi^{2}=91, \quad d f=55 ; \quad \chi^{2} / d f=1.6 ; \quad\right.$ CFI $=.930$; RMSEA $=.071)$ and scalar invariance $\left(\chi^{2}=97, d f=62 ; \chi^{2}\right.$ $d f=1.5 ; \mathrm{CFI}=.933$; RMSEA $=.065$ ). These results imply that the one-factor structure for the AFQ-Y is similar for boys and girls.

\section{Relationship Between Psychological Inflexibility and Symptoms of Anxiety in Children}

The correlations between psychological inflexibility and symptoms of anxiety in children are depicted in Table 2. The correlation between psychological inflexibility and anxiety symptoms was modest, but significant, $r(265)=.27$, $p<.01$. Further exploration of the data, showed that children with SCARED-71 anxiety scores above the clinical cut-off ( $n=78$ ), had higher scores than children with scores within the normal range $(n=189)$ on experiential avoidance (clinical scores: $M=6.60, S D=4.29$; non-clinical scores: $M=5.47, S D=4.25), t(265)=-1.98, p=.048$, on inaction or behavioral ineffectiveness, (clinical scores: $M=7.54, S D$ $=5.28$; non-clinical scores: $M=5.41, S D=4.56), t(265)=$ $-3.31, p=.001$, on psychological inflexibility measured with 17 items (clinical scores: $M=21.82, S D=13.25$; nonclinical scores: $M=17.17, S D=12.52), t(265)=-2.71, p$ $=.007$, and on psychological inflexibility measured with 8 items (clinical scores: $M=8.73, S D=6.21$; non-clinical scores: $M=6.69, \quad \mathrm{SD}=5.79), \quad t(265)=-2.57, \quad p=.01$. Children with scores within the clinical range also scored higher, although not significant, on cognitive fusion, (clinical scores: $M=7.68, S D=5.70$; non-clinical scores: $M=$ $6.30, S D=5.13), t(265)=-1.93, p=.054$.

\section{Discussion}

The current study sought to examine the usefulness and possibility of measuring psychological flexibility in middleaged children (i.e., aged 8-11 years) and specifically investigated the relationship between psychological in ${ }^{-}$exibility (the opposite of psychological flexibility) and symptoms of anxiety in children. Psychological flexibility is the main outcome of ACT. Insight into the usefulness and possibility of measuring psychological flexibility is an important step to enable studies on the effectiveness of ACT in middle-aged children. For this purpose, we examined the factor structure and construct validity of the Avoidance and Fusion Questionnaire for Youth, a questionnaire that taps psychological inflexibility in children and adolescents. 
Table 3 Summary of confirmatory factor analysis results for psychological inflexibility $(N=267)$

Factor loadings

\begin{tabular}{|c|c|c|c|c|}
\hline \multirow[b]{2}{*}{ Item, (number of item in questionnaire) ${ }^{\mathrm{a}}$} & \multicolumn{3}{|c|}{ 3-factor model AFQ-Y } & \multirow{2}{*}{$\begin{array}{l}\text { 1-factor model } \\
\text { AFQ-Y8 }\end{array}$} \\
\hline & $\begin{array}{l}\text { Cognitive } \\
\text { fusion }\end{array}$ & $\begin{array}{l}\text { Exper. } \\
\text { avoidance }\end{array}$ & Inaction & \\
\hline My life won't be good until I feel happy $(1)^{\mathrm{b}}$ & 1.000 & - & - & 1.000 \\
\hline My thoughts and feelings mess up my life $(2)^{\mathrm{b}}$ & 1.087 & - & - & 1.392 \\
\hline If I feel sad or afraid, something must be wrong with me (3) & 0.931 & - & - & \\
\hline The bad things I think about myself must be true $(4)^{\mathrm{b}}$ & 0.924 & - & - & 1.128 \\
\hline I can't stand to feel pain or hurt in my body (9) & 1.348 & - & - & \\
\hline If my heart beats fast, there must be something wrong with me $(10)^{\mathrm{b}}$ & 0.904 & - & - & 1.117 \\
\hline I am afraid of my feelings $(16)^{\mathrm{b}}$ & 1.192 & - & - & 1.563 \\
\hline I must get rid of my worries and fears so I can have a good life (6) & - & 1.000 & - & - \\
\hline I try hard to erase hurtful memories from my mind (8) & - & 0.887 & - & - \\
\hline I push away thoughts and feelings that I don't like (11) & - & 0.564 & - & - \\
\hline I wish I could wave a magic wand to make all my sadness go away (15) & - & 0.940 & - & - \\
\hline I don't try out new things if I'm afraid of messing up (5) & - & - & 1.000 & - \\
\hline I do all I can to make sure I don't look dumb in front of other people (7) & - & - & 1.224 & - \\
\hline I stop doing things that are important to me whenever I feel bad $(12)^{\mathrm{b}}$ & - & - & 0.751 & 1.137 \\
\hline I do worse in school when I have thoughts that make me feel sad $(13)^{\mathrm{b}}$ & - & - & 1.152 & 1.542 \\
\hline I say things to make me sound cool (14) & - & - & 0.475 & - \\
\hline I can't be a good friend when I feel upset $(17)^{\mathrm{b}}$ & - & - & 1.152 & 1.727 \\
\hline
\end{tabular}

${ }^{a}$ Dutch translation: 1. Mijn leven is pas goed als ik me gelukkig voel; 2. Mijn gedachten en gevoelens verpesten mijn leven; 3 . Als ik me verdrietig of bang voel, dan moet er iets mis met me zijn; 4. De slechte dingen die ik over mezelf denk, zijn vast waar; 5 . Ik probeer geen nieuwe dingen uit als ik bang ben om het te gaan verknoeien; 6 . Om een goed leven te krijgen, moet ik van mijn zorgen en angsten afkomen; 7. Ik doe er alles aan om er zeker van te zijn dat ik niet stom overkom bij anderen; 8. Ik doe erg mijn best om vervelende herinneringen te vergeten; 9 . Ik vind het vreselijk om ergens in mijn lichaam pijn of verdriet te voelen; 10. Als mijn hart snel klopt, is er vast iets mis met me; 11 . Gedachten en gevoelens die ik niet fijn vind, duw ik weg; 12. Als ik me slecht voel, stop ik met de dingen die belangrijk voor me zijn; 13. Ik doe het slechter op school wanneer ik gedachten heb die me verdrietig maken; 14. Ik zeg dingen waardoor ik cool overkom; 15. Ik zou willen dat ik met een toverstokje al mijn verdriet weg kon toveren; 16. Ik ben bang voor mijn gevoelens; 17. Als ik overstuur ben, kan ik geen goede vriend(in) zijn

$\mathrm{b}$ items retained on the AFQ-Y8

Greco et al. (2005) proposed a 17 -item version of the AFQ-Y as well as a shortened 8-item version (AFQ-Y8). Although the 17-item version is suitable to measure psychological inflexibility, as well as the three factors that constitute psychological inflexibility (cognitive fusion, experiential avoidance and behavioral ineffectiveness) in children from age 11 years on (Greco et al. 2008) and in adults (Fergus et al. 2011), this appeared not to be the case for the middle-aged children that constituted our sample. In contrast to our expectation, the fit indices were neither met for the three-factor structure, nor for the one-factor structure (psychological inflexibility) of the AFQ-Y. However, all fit indices were met for the shortened version, the AFQ-Y8. The shortened version does not distinguish between cognitive fusion, experiential avoidance and behavioral ineffectivess. These findings indicate that it would not be valid to distinguish between cognitive fusion, experiential avoidance and behavioral ineffectiveness in children aged
11 years and younger, and that the AFQ-Y8 seems more suitable in this population, rather than the 17 -item version of the AFQ-Y. We found comparable results for the factor structure of the AFQ-Y8 in boys and in girls, which means that the questionnaire taps psychological inflexibility equally well in boys and girls and no separate norms should be applied for boys and girls. Whereas the reliability of the AFQ-Y8 was questionable in young adolescents in the study of Greco et al. (2008), the reliability of the AFQ-Y8 was adequate to good in the current study with middle-aged children.

Even though Greco et al. (2008) did test the AFQ-Y in a small sample $(n=9)$ of middle-aged children and adapted the questionnaire based on the input children provided, the questionnaire was not validated any further in this age group. We found that the AFQ-Y8 is likely to be more appropriate for this age group than the 17 -item version. This is probably due to the complexity of the questions and the 
complexity of the answering categories. With regard to the complexity of the questions, capturing the concept psychological inflexibility in a questionnaire for children is a difficult task. Psychological inflexibility is an abstract concept and it requires meta-cognitive skills to answer questions like "my life won't be good until I feel happy". As Bond et al. (2011) put it: "psychological flexibility is a subtle construct that can be difficult to convey in short statements that are understandable to people uninitiated in ACT'. Although 8-10 year old children are able to reflect on their own thoughts, it can be argued that adolescents can grasp the concept of psychological inflexibility easier than younger children. In line, children expressed difficulties with the answering categories, ranging from not true at all to very true on a 5-point Likert scale, whereas they did not express difficulties with the answering categories of the SCARED-71 that range from "almost never" to "often" on a 3-point Likert scale. The AFQ-Y8 simply contains $50 \%$ less items than the AFQ-Y, and letting children complete this shorter version of the questionnaire asks less of their attention, which may positively affect the validity of the questions in this age group.

In line with our expectation, we found a positive relationship between psychological inflexibility and symptoms of anxiety in children. This is supportive for the construct validity of the questionnaire. If children are more anxious, their levels of psychological inflexibility increase and vice versa. Greco et al. (2008) also showed a significant positive relation between psychological inflexibility and symptoms of anxiety in older children. Children with anxiety could thus profit from targeting their psychological inflexibility, which is done in ACT. Additionally, we found that children with anxiety levels within the clinical range had significantly higher scores of psychological inflexibility than children with anxiety scores within the normal range. This could be a first indication of treatment sensitivity of the measure psychological flexibility for children with anxiety. Finally, the relationship between symptoms of anxiety and psychological inflexibility was found to be the strongest for panic disorder and the lowest for social and specific phobia. Panic disorder is characterized by extreme momentary fusion with one's panic thoughts and one's body signs, and these symptoms generalize to various circumstances. Specific phobia, on the other hand, is usually restricted to very specific objects or situations. The contrast between these disorders could explain their different relation to psychological inflexibility.

Psychological flexibility is the hallmark feature and the main outcome of ACT. However, to date, the measure of psychological inflexibility (AFQ-Y) had not been validated in middle-aged children. This study showed that the AFQY8 is suitable for measuring psychological inflexibility in middle-aged children. Being able to measure ACT's main outcome in middle-aged children is encouraging for clinicians and scientists who are interested in measuring the effectiveness of ACT in middle-aged children. Anxiety has the earliest age of onset of all psychiatric disorders (except for developmental disorders), and this study showed a positive relation between ACT's main outcome psychological inflexibility and anxiety in middle-aged children. ACT contains cognitive elements that require metacognitive reasoning skills, which middle-aged children master. Traditional CBT, however, contains cognitive elements that require abstract reasoning skills, which children acquire from eleven years of age onward. This makes ACT an interesting candidate for diminishing symptoms of dysfunctional child anxiety in middle-aged children.

\section{Limitations}

This study was performed in a community sample. On the one hand, this yields information for scientists and clinicians who seek to diminish early forms of dysfunctional anxiety. Prevention and early intervention initiatives usually recruit children from community samples. On the other hand, the fact that this study was performed in a community population hinders the generalizability of the findings to clinical populations. Clinical cut-offs still need to be determined. Therefore, it is of importance to replicate this study in children who were referred for their anxiety to a mental health center.

We did not collect information on the possible presence of anxiety disorders, but only used a questionnaire to measure symptoms of anxiety in children. Although the SCARED-71 has been validated (Bodden et al. 2009) and has been found to be predictive of anxiety disorders (Simon and Bögels 2009), the use of a diagnostic measure would provide more insight into the severity and the level of dysfunction of the child's anxiety. In addition, we did not collect any information on possible comorbid difficulties, such as depression.

In addition, we replaced the missing values by the item's median, which can be considered as a relatively unsophisticated strategy of replacing missing items. However, there were only a few missing items $(<0.3 \%$ of the items), and we prefer using straightforward analytic procedures whenever possible. Because of the large sample size and the small number of missing items, more complex methods were unlikely to change parameter estimates appreciably.

Finally, although this is the first study to examine the usefulness of the Dutch version of the questionnaire and the validity of the international version has been thoroughly examined in earlier studies, a full evaluation of the instrument requires that the validity and reliability of the questionnaire needs to be established more thoroughly in this age group. The predictive validity of the Dutch AFQ-Y8, 
and its construct and discriminant validity should be measured in various populations, psychological flexibility should be related to various constructs and types of psychopathology, and the AFQ-Y8 should be assessed at multiple points in time. Additionally, we did not test the validity of the AFQ-Y8 separately, but, instead, distilled the scores on the items from the completed 17-item versions of the AFQ-Y. Future investigators are advised to examine the validity of the AFQ-Y8.

\section{Compliance with Ethical Standards}

Conflict of interest The authors declare that they have no competing interests.

\section{References}

Achenbach, T. M., Howell, C. T., McConaughy, S. H., \& Stranger, C. (1995). Six-year predictors of problems in a national sample of children and youth: I. Cross-informant syndromes. Journal of the American Academy of Child \& Adolescent Psychiatry, 34, 336-347.

Arbuckle, J. L. (2011). Amos 20 User's Guide IBM.

Beesdo, K., Knappe, S., \& Pine, D. S. (2009). Anxiety and anxiety disorders in children and adolescents: developmental issues and implications for DSM-V. Psychiatric Clinics of North America, $32,483-524$

Billow, R. M. (1981). Observing spontaneous metaphor in children. Journal of Experimental Child Psychology, 31, 430-445.

Birmaher, B., Khetarpal, S., Brent, D., Cully, M., Balach, L., \& Kaufman, J. (1997). The screen for child anxiety related emotional disorders (SCARED): scale construction and psychometric characteristics. Journal of the American Academy of Child and Adolescent Psychiatric Clinics of North America, 36, 545-553.

Bodden, D. H. M., Bögels, S. M., \& Muris, P. (2009). The diagnostic utility of the screen for child anxiety related emotional disorders71 (SCARED-71). Behaviour Research and Therapy, 47, 418-425.

Bodden, D. H. M., Dirksen, C. D., \& Bögels, S. M. (2008). Societal burden of clinically anxious youth referred for treatment: a costof-illness study. Journal of Abnormal Child Psychology, 36, 487-497.

Bond, F. W., Hayes, S. C., Baer, R. A., Carpenter, K. M., Guenole, N., Orcutt, H. K., \& Zettle, R. D. (2011). Preliminary psychometric properties of the acceptance and action questionnaire-ii: a revised measure of psychological inflexibility and experiential avoidance. Behavior Therapy, 42, 676-688.

Cartwright-Hatton, S., McNicol, K., \& Doubleday, E. (2006). Anxiety in a neglected population: prevalence of anxiety disorders in preadolescent children. Clinical Psychology Review, 26, 817-833.

Coyne, L. W., McHugh, L., \& Martinez, E. R. (2011). Acceptance and commitment therapy (ACT): advances and applications with children, adolescents and families. Child and Adolescent Psychiatric Clinics of North America, 20, 379-399.

de Groot, F., Kleen, M., \& Rokx, A. T. A. J. J. (2008). Theoretische achtergronden van ACT. In J. A. Tjak \& F. de Groot (Eds.), Acceptance and commitment therapy: Een praktische inleiding voor hulpverleners (pp. 9-16). Houten: Bohn Stafleu van Lochum.

Fergus, T. A., Valentiner, D. P., Gillen, M. J., Hiraoka, R., Twohig, M. P., Abramowitz, J. S., \& McGrath, P. B. (2011). Assessing psychological inflexibility: the psychometric properties of the avoidance and fusion questionnaire for youth in two adult samples. Psychological Assessment, 24, 402-408.

Fledderus, M., Bohlmeijer, E. T., Smit, F., \& Westerhof, G. J. (2010). Mental health promotion as a new goal in public mental health care: a randomized controlled trial of an intervention enhancing psychological flexibility. American Journal of Public Health, $100,2372-2378$.

Goodman, T. A. (2005). Working with children: beginner's mind. In C. K. Germer, R. D. Siegel \& P. R. Fulton (Eds.), Mindfulness and psychotherapy (pp. 197-219). New York: Guilford.

Greco, L. A., Lambert, W., \& Baer, R. A. (2008). Psychological inflexibility in childhood and adolescence: development and evaluation of the avoidance and fusion questionnaire for youth. Psychological Assessment, 20, 93-102.

Greco, L. A., Murrell, A. R., \& Coyne, L. W. (2005). The Avoidance and Fusion Questionnaire for Youth. Unpublished manuscript.

Hayes, S. C., \& Gifford, E. V. (1997). The trouble with language: experiential avoidance, rules, and the nature of private events. Psychological Science, 8, 170-175.

Hayes, S. C., Luoma, J. B., Bond, F. W., Masuda, A., \& Lillis, J. (2006). Acceptance and commitment therapy: model, processes and outcomes. Behaviour Research and Therapy, 44, 1-25.

Hayes, S. C., \& Strosahl, K. D. (2004). A practical guide to acceptance and commitment therapy. New York, NY: Springer.

Hayes, S. C., Strosahl, K. D., \& Wilson, K. G. (1999). Acceptance and commitment therapy: An experiential approach to behavior change. New York: Guilford Press.

Heffner, M., Greco, L. A., \& Eifert, G. H. (2003). Pretend you are a turtle: children's responses to metaphorical versus literal relaxation instruction. Child and Family Behavior Therapy, 25, 19-33.

Heffner, M., Sperry, J., Eifert, G. H., \& Detweiler, M. (2002). Acceptance and commitment therapy in the treatment of an adolescent female with anorexia nervosa: a case example. Cognitive and Behavioral Practice, 9, 232-236.

Kabat-Zinn, J. (1990). Full catastrophe living: Using the wisdom of your body and mind to face stress, pain and illness. New York: Delacorte.

Kendall, P. C., Reber, M., McLeer, S., Epps, J., \& Ronan, K. R. (1990). Cognitive-behavioral treatment of conduct-disordered children. Cognitive Therapy and Research, 14, 279-297.

Kessler, R. C., Berglund, P., Demler, O., Jin, R., Merikangas, K. R., \& Walters, E. E. (2005). Lifetime prevalence and age-of-onset distributions of DSM-IV disorders in the National Comorbidity Survey Replication. Archives of General Psychiatry, 62, 593-602.

Kline, R. B. (1998). Principles and practice of structural equation modeling. New York: The Guilford Press.

Kline, R. B. (2011). Principles and practice of Structural Equation Modeling. New York: Guilford Press.

Langley, A. K., Bergman, R. L., \& Piacentini, J. C. (2002). Assessment of childhood anxiety. International Review of Psychiatry, 1 , 102-113.

Luoma, J., \& Hayes, S. C. (2003). Cognitive defusion. In W. T. Donohue, J. E. Fisher \& S. C. Hayes (Eds.), Empirically supported techniques for cognitive behavior therapy: A step by step guide for clinicians. New York: Wiley.

McCurry, S. M., \& Hayes, S. C. (1992). Clinical and experimental perspectives on metaphorical talk. Clinical Psychology Review, 12, 736-785.

Muris, P., Dreesen, L., Bögels, S. M., Weckx, M., \& van Melick, M. (2004). A questionnaire for screening a broad range of DSM defined anxiety disorder symptoms in clinically referred children and adolescents. Journal of Child Psychology and Psychiatry and Allied Disciplines, 45, 813-820.

Muris, P., Mayer, B., Bartelds, E., Tierney, S., \& Bogie, S. (2001). The revised version of the Screen for Child Anxiety Related Emotional Disorders (SCARED-R): treatment sensitivity in an 
early intervention trial for childhood anxiety disorders. British Journal of Clinical Psychology Review, 40, 323-336.

Muris, P., Merkelbach, H., Schmidt, H., \& Mayer, B. (1999a). The revised version of the screen for child anxiety related emotional disorders (SCARED-R): factor structure in normal children. Personality and Individual Differences, 26, 99-112.

Muris, P., Merkelbach, H., Van Brakel, A., \& Mayer, B. (1999b). The screen for child anxiety Related emotional disorders (SCARED): further evidence for its reliability and validity. Anxiety, Stress and Coping, 12, 411-425.

Murrell, A. R., Coyne, L. W., \& Wilson, K. G. (2004). ACT with children, adolescents, and their parents. In S. C. Hayes \& K. D. Strosahl (Eds.), A practical guide to acceptance and commitment therapy. New York: Springer.

Myers, K., \& Winters, N. C. (2002). Ten-year review of rating scales. I: overview of scale functioning, psychometric properties and selection. Journal of the American Academy of Child \& Adolescent Psychiatry, 41, 114-122.

Rector, N. (2013). Acceptance and commitment therapy: empirical considerations. Behavior Therapy, 44, 213-217.

Ronen, T. (1997). Cognitive developmental therapy with children. Chichester: Wiley.

Rosseel, Y. (2012). Lavaan: an R package for structural equation modeling. Journal of Statistical Software, 48, 1-36.
Simon, E., \& Bögels, S. M. (2009). Screening for anxiety disorders in children. European Journal of Child and Adolescent Psychiatry, $18,625-634$.

Simon, E., Otto, M., Gunther, N., \& Bögels, S. M. (in preparation). Do child- and parent-focused interventions for child anxiety improve family functioning and parenting styles?

Simon, E., van der Sluis, C., Muris, P., Thompson, E., \& CartwrightHatton, S. (2014). Anxiety in preadolescent children: what happens if we don't treat it, and what happens if we do? Psychopathology Review, 1, 28-50.

Swain, J., Hancock, K., Hainsworth, C., \& Bowmanb, J. (2013). Acceptance and commitment therapy in the treatment of anxiety: a systematic review. Clinical Psychology Review, 33, 965-978.

Tabachnick, B. G., \& Fidell, L. S. (2007). Using multivariate statistics (Fifth ed.). Boston.

Team, R. C. (2013). A language and environment for statistical computing. Paper presented at the The R Foundation for Statistical Computing, Vienne, Austria. http://www.R-project.org/.

Thulin, U., Svirsky, L., Serlachius, E., Andersson, G., \& Öst, L. (2014). The effect of parent involvement in the treatment of anxiety disorders in children: a meta-analysis. Cognitive Behaviour Therapy, 43, 185-200.

Van de Schoot, R., Lugtig, P., \& Hox, J. (2012). A checklist for testing measurement invariance. European Journal of Developmental Psychology. doi: 10.1080/17405629.2012.686740. 